\title{
Erratum to: Evaluation of psychological and pedagogical strategies for creating gender motivation in modern glossy magazines as an "Overton Window" in an electronic and digital society
}

\author{
Ardak Mutalieva, ${ }^{1}$ Irina Savchuk $^{2 *}$, Laura Orazgaliyeva ${ }^{3}$, Gulzhanar Jumazhanova, ${ }^{4}$ \\ Akmaral Zhumykbayeva, ${ }^{5}$ Eugenia Sheveleva ${ }^{6}$ \\ ${ }^{1}$ Eurasian National University, 2 Pushkin St, Nur-Sultan, 010008, Kazakhstan, Nur-Sultan \\ ${ }^{2}$ Yuga State University, 16 Chekhov St, Khanty-Mansiysk, 628007, Russian Federation, Khanty-Mansiysk \\ ${ }^{3}$ Astana IT University, EXPO business center, block C.1, Nur-Sultan, 010000, Kazakhstan, Nur-Sultan \\ ${ }^{4}$ Astana IT University, EXPO business center, block C.1, Nur-Sultan, 010000, Kazakhstan, Nur-Sultan \\ ${ }^{5}$ Eurasian National University, 2 Pushkin St, Nur-Sultan, 010008, Kazakhstan, Nur-Sultan \\ ${ }^{6}$ Moscow State Linguistic University, 38, Ostozhenka St, Moscow, 119034, Russian Federation
}

Original article:

SHS Web of Conferences (LLT Forum 2020)

Volume 88, 2020

International Scientific Forum "Issues of Modern Linguistics and the Study of Foreign Languages in the Era of Artificial Intelligence (dedicated to World Science Day for Peace and Development)" (LLT Forum 2020)

https://doi.org/10.1051/shsconf/20208801027

The name of the fourth author of the article (Gulnar Jumazhanova) should be replaced by the name Gulzhanar Jumazhanova, the affiliation of the fourth author (Astana IT University, EXPO business center, block C.1, Nur-Sultan, 010000, Kazakhstan, Nur-Sultan) should be replaced by the following institution and its address: Shakarim University of Semey, Semey, 070000, Kazakhstan, Semey 